\title{
DRESS syndrome due to clobazam: a case report
}

\author{
M. Faraz Qureshi*, A. N. Dattatri \\ Department of Pharmacology, Karnataka Institute of Medical Sciences, Hubballi, Karnataka, India \\ Received: 05 October 2020 \\ Revised: 08 November 2020 \\ Accepted: 09 November 2020 \\ *Correspondence: \\ Dr. Md Faraz Qureshi, \\ Email: faraz.m4@gmail.com
}

Copyright: (c) the author(s), publisher and licensee Medip Academy. This is an open-access article distributed under the terms of the Creative Commons Attribution Non-Commercial License, which permits unrestricted non-commercial use, distribution, and reproduction in any medium, provided the original work is properly cited.

\begin{abstract}
Drug rash (or reaction) with eosinophilia and systemic symptoms (DRESS) is a potentially life-threatening hypersensitivity reaction to drugs characterized by rash, fever, lymphadenopathy, hematologic abnormalities, and involvement of internal organs. Initially coined in 1996, the term is used to refer to an idiosyncratic reaction to several drugs, the most common of which are carbamazepine, allopurinol, sulfasalazine, and phenobarbital. We report the case of DRESS related to clobazam in a 38-year-old female with a history of a complex seizure disorder.
\end{abstract}

Keywords: Clobazam, DRESS syndrome, Epilepsy, Rash

\section{INTRODUCTION}

DRESS is a form of severe cutaneous adverse reactions (SCARs). SCARs includes four other druginduced skin reactions, the Stevens-Johnson syndrome; toxic epidermal necrolysis; StevensJohnson/toxic epidermal necrolysis overlap syndrome; and acute generalized exanthematous pustulosis.

All SCARs disorders have similar pathogenesis. ${ }^{1}$ DRESS syndrome usually occur after two to six weeks of initiating drug therapy and may persist or worsen, even after the termination of medication. Incidence of DRESS syndrome ranges from 1 in 1000 to 1 in 10,000 drug exposures, most common drugs implicated are anticonvulsants. Along with skin rash, there is also fever, lymph node enlargement, hematologic abnormalities, and internal organ involvement. Liver is the primarily affected organ, but other organs such as the kidneys, lungs, heart, and pancreas may also be involved. New strategies are in use or under development to screen individuals at risk for DRESS to aid them in avoiding medications that increase the risk of DRESS. ${ }^{2,3}$

\section{CASE REPORT}

A 38-years-old female was admitted to our hospital with complaints of fever, rashes all over the body, swelling of lips, generalised oedema for 3 days. The patient was diagnosed as an epileptic 20 years ago and was prescribed phenytoin. She took the medication for 5-6 years and stopped thereafter as she did not have any seizures then. Recently, the patient developed few episodes of recurring seizures for which she was put on phenytoin. She took the tablets for 2 months, but the seizure episodes were not controlled adequately. Hence, the dose of phenytoin was increased and tab. clobazam was added. The patient was on this combined treatment for the past 1 month but developed skin rash lately and hence this combination was stopped and the patient was started on tab. levetiracetam by the neurologist; since then seizures were under control. The opinion of dermatologist was sought for skin rash. On physical examination, multiple erythematous maculopapular rashes were present over the trunk, and both upper and lower limbs, oedema was present over the face around the periorbital region with angioedema of lips and erosion of the oral cavity. The extent of the rash was $>50 \%$ of the 
body surface area. Laboratory investigations revealed leucocytosis and deranged liver function tests. Creatinine, blood urea, blood sugar, and electrolyte levels were within normal limits. The patient scored 4 points when Regi SCAR scoring system was applied.

The probable diagnosis was DRESS syndrome. The patient was treated with cefotaxime IV, ranitidine IV, paracetamol PO, fluconazole PO, multivitamins PO, chlorhexidine mouth wash, clotrimazole mouth paint, benzocaine, and triamcinolone gels and liquid paraffin for local application and she recovered clinically.

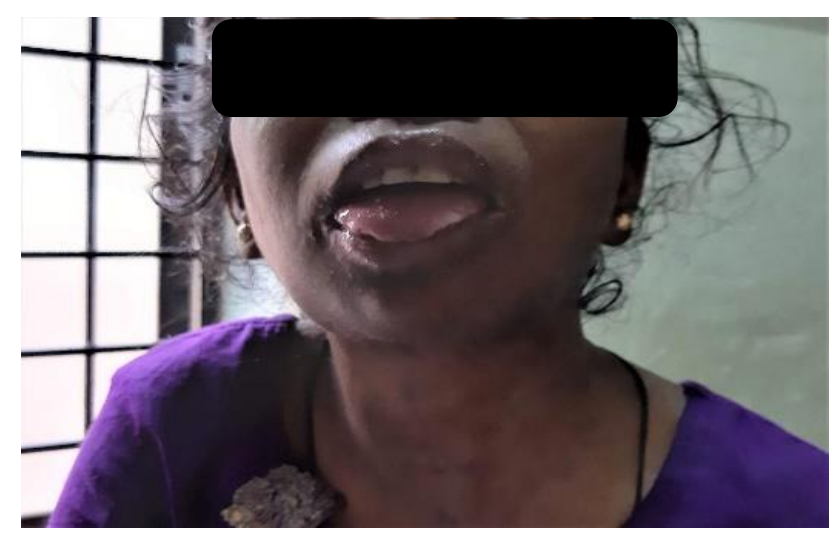

Figure 1: Maculopapular eruptions on neck, face and oral cavity with erosions in oral mucosa.

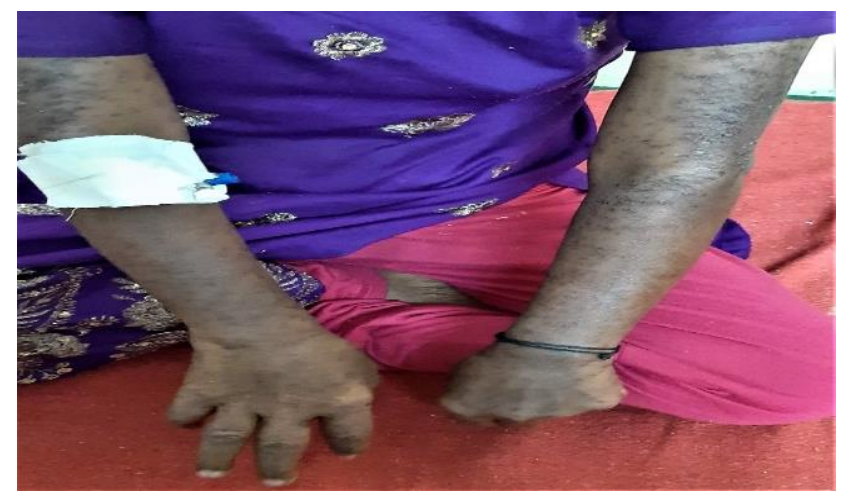

Figure 2: Maculopapular lesions with scab on upper limb.

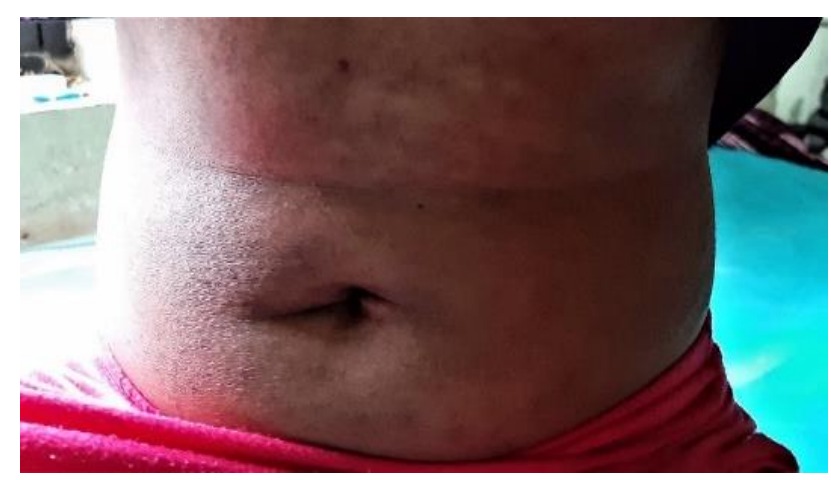

Figure 3: Maculopapular lesion with scab on abdomen and trunk.

\section{DISCUSSION}

The patient of DRESS syndrome presents with rash, hematologic abnormalities, lymphadenopathy, and organ involvement, including liver and kidney. The mortality of DRESS syndrome is as high as $10 \%{ }^{4,5}$ DRESS syndrome has a prevalence of about 2.18 per 100,000 patients. ${ }^{2,6}$ It develops secondary to an accumulation of toxic drug metabolites due to various enzymatic deficiencies. ${ }^{4}$

This condition is multifactorial in origin and may include an immune-mediated hypersensitivity component that is due to interaction between the drugs or their metabolites and a genetic susceptibility, however, the aetiology is not yet clear. ${ }^{7}$ Factors which are considered as trigger for DRESS syndrome includes, drugs, viruses (mainly herpes virus 6 [HHV6], but also HHV7, Epstein-Barr virus, and cytomegalovirus) and the immune system. ${ }^{8}$ Clinical conditions, such as acute viral infections, hepatitis, sepsis, autoimmune disease, and hematologic disorders, should be considered in the differential diagnosis of DRESS syndrome.

Most of the patients, presents with skin rash, liver involvement, hypereosinophilia, and lymphadenopathy. ${ }^{9}$ Morbilliform skin eruptions occur in the form of infiltrative lesions, scaling, and/or purpura which affects over $50 \%$ the body. ${ }^{9}$

In DRESS syndrome, most commonly affected organ is the liver. Although its involvement is generally mild, it could cause high liver chemistry elevations with rare progression to fulminant hepatic failure. ${ }^{10}$ In DRESS syndrome, haematological findings are common, eosinophilia being the most common manifestation, that often gets delayed by 1-2 weeks. ${ }^{10-12}$ Sometimes, renal dysfunction is also observed. ${ }^{11}$

DRESS syndrome is a challenging diagnosis-suspicion should arise if patients present with the above-mentioned characteristic symptoms after receiving a new high-risk medication in the previous 2-6 weeks. Diagnostic criteria used for DRESS syndrome consist of, Bocquet's diagnostic criteria, the presence of three conditions such as drug-induced skin eruption, eosinophilia $\geq 1500 / \mathrm{mm}$, and at least one of the following systemic abnormalities: lymphadenopathy, hepatitis (LFTs >2 ULN), interstitial nephropathy, interstitial lung disease, or myocardial involvement would confirm the diagnosis. ${ }^{2}$ RegisSCAR criteria classify the patient as "probable" of having DRESS syndrome. ${ }^{13}$ Causality analysis using Naranjo's scale showed that clobazam was the probable cause of the adverse reaction in our case (score $=6$ ).

Management is supportive treatment and prompt withdrawal of the offending drug. If significant liver injury is suspected, n-acetyl-cysteine is administered. These reduce the chances of complications and death. However, complete recovery requires weeks to months 
for most patients. Systemic corticosteroids are used; however, they have not produced significant benefit. ${ }^{14}$

\section{CONCLUSION}

When starting any new antiepileptic medication, the clinicians should be aware of the possibility of the severe hypersensitivity reaction. When patients present with skin rash and systemic abnormalities after recent changes in medications, DRESS syndrome should be considered as a possible differential diagnosis by the treating physician and more aggressive therapy should be used, if cessation of implicated drug does not result in clinical improvement of the patient. Early diagnosis and specialised supportive care are the key to management of DRESS syndrome.

Funding: No funding sources

Conflict of interest: None declared

Ethical approval: Not required

\section{REFERENCES}

1. Adler NR, Aung AK, Ergen EN, Trubiano J, Goh MS, Phillips EJ. Recent advances in the understanding of severe cutaneous adverse reactions. Bri J Dermatol. 2017;177(5):1234-47.

2. Bocquet H, Bagot M, Roujeau JC. Drug induced pseudolymphoma and drug hypersensitivity syndrome (Drug rash with eosinophilia and systemic symptoms: DRESS). Semin Cutan Med Surg. 1996;15:250-7.

3. Cacoub P, Musette P, Descamps V, Meyer O, Speirs $\mathrm{C}$, Speirs $\mathrm{C}$ et al. The Dress syndrome: a literature review. Am J Med. 2011;124(7):588-97.

4. Choudhary S, Mcleod M, Torchia D, Romanelli P. Drug reaction with eosinophilia and systemic symptoms (DRESS) syndrome. J Clin Aesthet Dermatol. 2013;6:31-7.

5. Seth D, Kamat D, Montejo J. DRESS syndrome: a practical approach for primary care practitioners. Clin Pediatr (Phila). 2008;47:947-52.

6. Wolfson AR, Zhou L, Li Y, Phadke NA, Chow OA, Blumenthal KG. Drug reaction with eosinophilia and systemic symptoms (DRESS) syndrome identified in the electronic health record allergy module. J Allergy Clin Immunol Pract. 2019; 7:633-40.

7. Besli GE, Yldrm S, Ylmaz K, Yuksel E. Drug reaction with eosinophilia and systemic symptoms syndrome or hematologic malignancy? A case report of a 4-year-old boy. Pediatr Emerg Care. 2017;33:494-6.

8. Marcus N, Smuel K, Almog M, Prais D, Straussberg $\mathrm{R}$, Landau D et al. Successful intravenous immunoglobulin treatment in pediatric severe DRESS syndrome. J Allergy Clin Immunol Pr. 2018;6:1238-42.

9. Eshki M, Allanore L, Musette P, Milpied B, Grange A, Guillaume JC et al. Twelve year analysis of severe cases of drug reaction with eosinophilia and systemic symptoms: a cause of unpredictable multiorgan failure. Arch Dermatol. 2009;145(1):6772.

10. Tas S, Simonart T. Drug rash with eosinophilia and systemic symptoms (DRESS syndrome). Acta Clin Belg. 1999;54:197-200.

11. Kano Y, Ishida T, Hirahara K, Shishara T. Visceral involvements and long term sequelae in drug induced hypersensitivity syndrome. Med Clin North Am. 2010;94:743-59.

12. Husain Z, Reddy BY, Schwartz RA. Dress syndrome part 1 - clinical perspective. J Am Acad Dermatol. 2013;68:693.

13. Pannu A, Saroch A. Diagnostic criteria for drug rash and eosinophilia with systemic symptoms. J Fam Med Prim Care. 2017;6:693-4.

14. Ichai P, Laurent-Bellne A, Saliba F, Moreau D, Besch C, Francoz C et al. Acute liver failure/injury related to drug reaction with eosinophilia and systemic symptoms: outcome and prognostic factors. Transplantation. 2017;101(8):1830-7.

Cite this article as: Qureshi MF, Dattatri AN. DRESS syndrome due to clobazam: a case report. Int J Basic Clin Pharmacol 2020;9:1906-8. 